\title{
Identification of iron deficiency chlorosis tolerant sources from mini-core collection of groundnut (Arachis hypogaea L.)
}

\author{
Santosh K. Pattanashetti*十, Gopalakrishna K. Naidu, Prakyath Kumar K.V., \\ Omprakash Kumar Singh and Basavaraj D. Biradar \\ Department of Genetics and Plant Breeding, College of Agriculture, Vijayapur - 586101, University of \\ Agricultural Sciences, Dharwad, India
}

Received 22 June 2017; Accepted 27 October 2017

\begin{abstract}
Iron deficiency chlorosis (IDC) is common among groundnut grown in calcareous and alkaline soils in India, China and Pakistan and causes considerable reduction in pod yield. To identify genetically diverse IDC tolerant accessions, the mini-core collection of groundnut representing geographical diversity was evaluated for IDC response over 2 years in iron-deficient calcareous soils. Enormous genetic variability was evident in the mini-core collection for IDC tolerance-related traits such as a visual chlorotic rating (VCR) and SPAD chlorophyll meter reading (SCMR) across five growth stages. Several IDC tolerant sources belonging to different botanical varieties such as hypogaea bunch (ICG \# 5051, 6766, 5286, 6667, 4538, 14008, 5663, 9842, 11855), hypogaea runner (ICG 10479), fastigiata (ICG 10890) and vulgaris (ICG \# 11651, 118) were identified. Among the six botanical varieties of groundnut, hypogaea bunch types were found most tolerant to IDC and this is the first report in groundnut. The IDC tolerant sources identified were irrespective of their country of origin. The principal component analysis based on VCR, SCMR, pod yield and its related traits revealed five major principal components that explained $80 \%$ of the total variation. The biplot generated using PC1 and PC2 revealed a distinct separation of IDC tolerant genotypes from the susceptible ones. The hierarchical clustering using five major principal components revealed seven major clusters that were mainly based on IDC response of the accessions.
\end{abstract}

Keywords: botanical variety, genetic variability, peanut, SPAD chlorophyll meter reading, visual chlorotic rating

\section{Introduction}

Iron deficiency chlorosis (IDC) is common among the crops grown in calcareous, alkaline, coarse-textured, eroded and low organic matter containing and cold region soils where $\mathrm{Fe}$ is mostly found in insoluble ferric $\left(\mathrm{Fe}^{3+}\right)$ form but very less in available ferrous $\left(\mathrm{Fe}^{2+}\right)$ form, hence, Fe is less available for uptake by the plants (Ye et al., 2015).

\footnotetext{
*Corresponding author. E-mail: S.Pattanashetti@cgiar.org, santosh. pattanashetti@gmail.com

+Present address: Genebank, International Crops Research Institute for the Semi-Arid Tropics, Patancheru - 502324, India.
}

Groundnut has been reported to be sensitive to Fe deficiency in alkaline and calcareous soils (Singh, 2004; Zuo and Zhang, 2011; Sánchez-Alcalá et al., 2014). On the world scale, it is estimated that Fe deficiency occurs in about $30-50 \%$ of cultivated soils (Cakmak, 2002). More than one-third of the soils in India are calcareous and spread mostly in the low rainfall areas of the western and central parts of the country. Groundnut being a major crop in these areas, IDC causes a considerable reduction (16-32\%) in pod yield (Singh et al., 1995; Singh, 2001). Similarly, IDC is a common problem in groundnut producing areas with calcareous soils in northern China (Gao and Shi, 2007), and Pakistan (Imtiaz et al., 2010; Akhtar et al., 2013). Further, iron deficiency can also lead to the 
reduced content of Fe in plant products thereby causing anaemia in animals and humans (Guerinot and Yi, 1994).

In groundnut, iron deficiency initially appears as chlorosis on young rapidly expanding leaves with characteristic interveinal chlorosis. Under severe iron deficiency, veins also become chlorotic, leaves become white and papery and later turn brown and necrotic, and plants show stunted growth resulting in reduced yield (Singh et al., 2004), seed Fe content (Boodi et al., 2015a), and fodder (Prasad et al., 2000). The acute iron deficiency would lead to plant death and complete crop failure. Application of Fe fertilizer in the form of inorganic, chelated and organic formulations has been suggested to overcome the Fe deficiency in plants (Laurie et al., 1991), but these practices are either inefficient (Hüve et al., 2003) or economically not feasible in the semiarid tropics where groundnut is mainly grown as a rainfed subsistence crop. Hence, development of IDC tolerant groundnut cultivars for iron deficient calcareous soils would serve as a sustainable solution. The reduced subsets of germplasm such as core (Frankel, 1984) or mini core (Upadhyaya and Ortiz, 2001) collections that represent geographical diversity would act as a cost-effective means of identifying diverse accessions having resistance or tolerance to biotic and abiotic stress, agronomic and nutritional quality traits. The mini-core collection (184 accessions) of groundnut that represents geographical diversity was constituted earlier at ICRISAT (Upadhyaya et al., 2002) and has been extensively used to identify agronomically desirable, abiotic and biotic stress resistant or tolerant and nutritionally dense groundnut germplasm (Upadhyaya et al., 2014). In the present study, the groundnut mini-core collection was evaluated to identify diverse sources of IDC tolerance for further utilization in groundnut breeding programme.

\section{Materials and methods}

\section{Experimental material and design}

The experimental material used in this investigation was groundnut mini-core collection that comprises 184 accessions belonging to two subspecies (fastigiata and bypogaea) and six botanical varieties (bypogaea bunch/ runner 85 accessions; vulgaris 58 accessions; fastigiata 37 accessions; peruviana two accessions; aequatoriana and hirsuta one accession each) (Upadhyaya et al., 2002). In addition, four controls [ICG 156 hypogaea runner; ICG 13942 hypogaea bunch; ICG 13941 vulgaris; ICG 2738 fastigiata] and eight checks with varying levels of IDC response [tolerant - ICGV-06146, ICGV-86031, A30b; moderately susceptible - GPBD-5, DSG-1; susceptible - R-9227, TMV-2, GPBD-4] were used. A total of 196 genotypes were evaluated in unbalanced alpha design in the irondeficient calcareous soils (DTPA extractable $\mathrm{Fe}<4 \mathrm{mg} / \mathrm{kg}$ ) (online Supplementary Table S1) at College of Agriculture, Vijayapur $\left(16^{\circ} 49^{\prime} \mathrm{N}, 75^{\circ} 43^{\prime} \mathrm{E}, 593 \mathrm{~m}\right.$ above mean sea level) under University of Agricultural Sciences, Dharwad, India during two consecutive rainy seasons (June-October) of 2014 and 2015. The plot size for each genotype was one row of $3 \mathrm{~m}$ length with two replicates, wherein vulgaris, fastigiata, peruviana, aequatoriana and hypogaea bunch (erect types) were sown at an inter- and intra-row spacing of 30 and $10 \mathrm{~cm}$, while hypogaea runner and hirsuta (runner types) at 60 and $10 \mathrm{~cm}$, respectively. The recommended cultivation practices were followed to raise a good crop and protective irrigation was provided under severe moisture stress. All the major nutrients $(\mathrm{N}, \mathrm{P}, \mathrm{K})$ were supplied in the form of urea, diammonium phosphate and muriate of potash fertilizers as per recommended dose. Micronutrients like $\mathrm{Zn}, \mathrm{Mn}$ and $\mathrm{Mg}$ were applied in the form of $\mathrm{ZnSO}_{4}, \mathrm{MnSO}_{4}$ and $\mathrm{MgSO}_{4}$ at recommended level to avoid the complexity of overlapping deficiency symptoms with Fe. But, iron-containing fertilizers were not applied to maintain the iron deficiency status of the calcareous soils.

\section{IDC response and yield-related traits}

The IDC response was assessed based on two related traits such as a visual chlorotic rating (VCR) and SPAD chlorophyll meter reading (SCMR). For VCR, the 1-5 scale proposed by Singh and Chaudhari (1993) based on severity and coverage of interveinal chlorosis in entire plant was followed [ 1 - normal green leaves with no chlorosis, 2 - green leaves with slight chlorosis on some leaves, 3 - moderate chlorosis on several leaves, 4 - moderate chlorosis on most of the leaves, 5 - severe chlorosis on all the leaves] (online Supplementary Fig. S1). The scoring was done based on overall expression of plants on plot basis at five different stages i.e. 20, 40, 60, 80 and 100 days after sowing (d). The minute differences in the deficiency symptoms of different relevant micronutrients were kept in mind while scoring. The chlorophyll meter SPAD 502 (Soil-plant analysis development meter, Konica Minolta) measures the absorbance of the leaf in the red and near-infrared region. Using these two transmittances, it calculates a numerical SPAD value which is proportional to the chlorophyll present in the leaf and is negatively related to chlorosis of the plants (Samdur et al., 2000). The SCMR values were recorded in the interveinal area of the standard leaf (third fully opened leaf from the top) of the five plants in a plot using SPAD 502 and mean was computed at five different stages i.e. 20, 40, 60, 80, and $100 \mathrm{~d}$. The mean performance of genotypes for traits such as plant height $(\mathrm{cm})$, number of primary branches per plant and number of mature pods per plant were recorded on five random plants at the time of harvest and mean was computed, while pod yield (g/ 
plant), shelling out turn (\%) and hundred seed weight (g) were recorded after thorough air drying of pods for all the genotypes.

\section{Chlorophyll and ferrous content}

At the severe stage of IDC incidence ( $60 \mathrm{~d}$ ) during the 2014 rainy season, 16 genotypes were selected including checks which belong to different botanical varieties with varying IDC response from tolerant to susceptible. The biochemical constituents such as chlorophyll content ( $\mathrm{a}, \mathrm{b}$ and total) and ferrous content were estimated among these genotypes to establish their correlation with IDC response traits such as VCR and SCMR at $60 \mathrm{~d}$. The standard leaves (third fully expanded leaf from the tip of the main stem) of the five plants per genotype were used for the estimation of chlorophyll and ferrous content.

\section{Chlorophyll estimation}

The chlorophyll content was estimated using the method of Shoaf and Lium (1976). Hundred $m g$ of fresh leaf tissue was cut into small pieces and incubated in $7 \mathrm{ml}$ of Dimethyl sulfoxide at $65^{\circ} \mathrm{C}$ for $30 \mathrm{~min}$. At the end of incubation period, the supernatant was decanted and leaf tissue was discarded. The supernatant volume was made up to $10 \mathrm{ml}$ and absorbance was recorded at 645,652 and $663 \mathrm{~nm}$ in UV-Vis spectrophotometer (ELICO make). The chlorophyll a, chlorophyll b and total chlorophyll content were calculated using the following formulae given by Arnon (1949) and expressed as $\mathrm{mg} / \mathrm{g}$ fresh weight of leaf.

$$
\begin{aligned}
& \text { Chlorophyll 'a' }= {\left[\left(12.7 \times \mathrm{A}_{663}\right)-\left(2.69 \times \mathrm{A}_{645}\right)\right] } \\
& \times \mathrm{V} / 1000 \times \mathrm{W} \times \mathrm{a} \\
& \text { Chlorophyll 'b' }= {\left[\left(22.9 \times \mathrm{A}_{645}\right)-\left(4.68 \times \mathrm{A}_{663}\right)\right] } \\
& \times \mathrm{V} / 1000 \times \mathrm{W} \times \mathrm{a} \\
& \text { Total Chlorophyll }=\text { Chlorophyll 'a' }+ \text { Chlorophyll 'b' }
\end{aligned}
$$

where $\mathrm{A}=$ absorbance at specific wave length $(645,663$ $\mathrm{nm}), \mathrm{V}=$ final volume of the chlorophyll extract $(\mathrm{ml})$, $\mathrm{W}=$ fresh weight of the leaf sample $(\mathrm{g}), \mathrm{a}=$ path length of light $(1 \mathrm{~cm})$

\section{Ferrous estimation}

The active iron (Ferrous, $\mathrm{Fe}^{2+}$ ) estimation was done as per the procedure of Katyal and Sharma (1980).

(i) Preparation of leaf sample - The samples were collected from the standard leaf of plants. The leaves were washed once with tap water followed by $0.1 \mathrm{~N}$ $\mathrm{HCl}$ and then rinsed with double distilled water. Further, the fresh leaves were chopped with a stainless steel knife and used for estimation of active iron content. (ii) Preparation of o-phenanthroline extracting solution To prepare 1 litre of o-phenanthroline extractant, $15 \mathrm{~g}$ of o-phenanthroline was added to about $850 \mathrm{ml}$ of distilled water. To this continuously stirring solution, approximately $1 \mathrm{~N} \mathrm{HCl}$ was added dropwise. When the last traces of the salt were soluble, the $\mathrm{pH}$ was determined and it was found to be about 5.5. The volume of the solution was made up to 1 litre.

(iii) Ferrous estimation - Two grams of chopped sample was transferred to $100 \mathrm{ml}$ capacity glass bottles. Twenty $\mathrm{ml}$ of o-phenanthroline solution was added and the contents of the bottles were stirred gently in order to embathe the plant sample with the extractant. The bottles were incubated for about $16 \mathrm{~h}$ at room temperature. The contents were filtered through Whatman No. 1 filter paper. The active iron was estimated directly in the filtrate by measuring the transmittance at $510 \mathrm{~nm}$ in UV-Vis spectrophotometer.

\section{Statistical analyses}

All the statistical analyses were performed using the GenStat 14.1 software (VSN International, 2011). The data of 2 years $(2014,2015)$ for all the traits were subjected to pooled analysis by restricted maximum likelihood (REML) analysis (Patterson and Thompson, 1971) with years (environment) as fixed and genotypes as random variables. The genotype $\left(\sigma^{2} \mathrm{~g}\right)$, genotype $\times$ environment $\left(\sigma^{2}\right.$ ge $)$ variances and residuals were calculated for the pooled data. The significance of the environments was tested using Wald (1943) statistic. Best linear unbiased predictors (BLUPs) were calculated for the genotypes and used for comparison by the least significant difference $(P=0.05)$. Mini core accessions belonging to the six botanical varieties were categorized based on their growth habit into four groups: group 1 ( $\mathrm{vul}$ garis) (58 accessions, control ICG 13941), group 2 (fastigiata + peruviana + aequatoriana) (40 accessions, control ICG 2738), group 3 (bypogaea bunch) (51 accessions, control ICG 13942) and group 4 (bypogaea runner + hirsuta) (35 accessions, control ICG 156). Mean comparison between these groups for VCR and SCMR across five stages and yield-related traits were made using Student-Newman-Keuls (SNK) method at $P=0.05$ (Newman, 1939; Keuls, 1952). Pearson correlation coefficients (r) were estimated to know the correlations between the IDC tolerance associated traits (VCR and SCMR) across five stages, yield and its related traits for the pooled data over 2 years, and significance was tested using table ' $r$ ' value $(P=0.05)$. Genetic components of variability such as genotypic coefficient of variation (GCV), phenotypic coefficient of variation (PCV) (Burton and Devane, 1953), broad sense heritability $\left(H_{\mathrm{bs}}\right)$ (Hanson et al., 1956) and genetic advance as percent of mean (GAM) (Johnson et al., 1955) were estimated. The GCV and PCV were 
categorized as low (0-10\%), moderate (10-20\%) and high $(>20 \%)$ as suggested by Sivasubramanian and Menon (1973). The $H_{\mathrm{bs}}$ were classified as low (0-30\%), moderate (30-60\%) and high (>60\%) as suggested by Robinson et al . (1949). The GAM were categorized as low (0-10\%), moderate (10-20\%) and high (>20\%) as suggested by Johnson et al. (1955). The principal component analysis (PCA) was performed using BLUPs of all traits. The hierarchical cluster analysis was performed by Ward's (1963) method using the Euclidian distances generated from five major principal components (PCs).

\section{Results}

\section{Variance components}

The REML analysis of pooled data over 2 years indicated significant genotype $\left(\sigma^{2} g\right)$ and genotype $\times$ environment $\left(\sigma^{2}\right.$ ge) variances for VCR and SCMR across five stages (20, $40,60,80$ and $100 \mathrm{~d})$, except genotypic variance $\left(\sigma^{2} \mathrm{~g}\right)$ for SCMR at $40 \mathrm{~d}$. Significant $\sigma^{2} \mathrm{~g}$ and $\sigma^{2}$ ge variances were also observed for pod yield and its related traits such as plant height, number of primary branches per plant, number of mature pods per plant, shelling out turn and hundred seed weight (online Supplementary Table S2). The Wald's statistic indicated significant differences between environments (years) for VCR (at 60, 80, 100 d) and SCMR $(60,100 \mathrm{~d})$ at later stages of crop growth when IDC incidence was more severe. Significant differences between environments were also observed for pod yield, shelling out-turn, plant height and number of primary branches, but non-significant for number of pods per plant and hundred seed weight.

\section{Genetic variability}

Enormous genotypic differences for IDC response in the groundnut mini-core collection were evident with wide variation observed for VCR and SCMR across five stages $(20,40,60,80$ and $100 \mathrm{~d})$ in iron-deficient calcareous soils (Table 1). The intensity of IDC increased from early to later stages (20-100 d) of the crop growth as evident from the grand mean of mini core accessions that showed an increase in VCR (1.42-2.83), while a decrease in SCMR (33.5-19.7). Enormous differences were also observed for pod yield (1.2-6.3g/plant) and its related traits such as plant height $(9.6-23.7 \mathrm{~cm})$, number of primary branches per plant (3.8-6.3), number of mature pods per plant (2.212.7), shelling out turn (49.3-65.3\%), and hundred seed weight (17.2-37.8) indicating the genotypic differences in mini core under iron deficiency stress. For VCR, the GCV values were moderate across all five stages, but PCV values were higher during initial stages $(20,40 \mathrm{~d})$ but moderate during later stages (60, 80, 100 d). For SCMR, GCV values were low during initial stages $(20,40 \mathrm{~d})$ and moderate to high during later stages $(60,80,100 \mathrm{~d})$, but PCV values were moderate during initial stages $(20,40,60 \mathrm{~d})$ and higher during later stages $(80,100 \mathrm{~d})$. The GCV values were high for pod yield, moderate for number of pods and plant height, and low for hundred seed weight, number of primary branches, and shelling out-turn. The PCV values were high for pod yield and number of pods, moderate for plant height, hundred seed weight, and number of primary branches, but low for shelling out-turn. The broad sense heritability $\left(H_{\mathrm{bs}}\right)$ values for VCR and SCMR were moderate at early stages (20, 40, $60 \mathrm{~d})$ when IDC symptoms were moderate, while higher at later stages $(80,100 \mathrm{~d})$ when IDC symptoms were severe. The $H_{\text {bs }}$ values were moderate for pod yield, number of pods, plant height, shelling out turn and number of primary branches, but high for hundred seed weight. The GAM values for VCR and SCMR across five stages were moderate to high. The GAM values were higher for pod yield and number of pods, moderate for plant height and hundred seed weight, but low for number of primary branches and shelling out-turn.

\section{Ferrous and chlorophyll content}

At the severe stage of IDC incidence ( $60 \mathrm{~d}$ ) during the 2014 Rainy season, 14 accessions of the mini core belonging to different botanical varieties with varying IDC response ranging from tolerant to susceptible were selected along with two checks (ICGV 86031 and R 9227) (Online Supplementary Table S3). The chlorophyll ('a', 'b' and total) and ferrous $\left(\mathrm{Fe}^{2+}\right)$ content in the standard leaf was estimated among these 16 genotypes to understand their relation with VCR and SCMR. The selected mini core accessions showed wide variation for chlorophyll ' $\mathrm{a}$ ' (0.149-1.846 mg/g), chlorophyll 'b' (0.026-0.394 mg/g), total chlorophyll $(0.175-2.240 \mathrm{mg} / \mathrm{g})$, and ferrous content $(3.73-9.16 \mathrm{mg} / \mathrm{kg}$ ) depending on the intensity of IDC. The mini core accessions with lower VCR and higher SCMR had high ferrous and chlorophyll ('a', 'b' and total) content than those accessions with higher VCR and lower SCMR irrespective of the botanical variety they belonged to. Ferrous and chlorophyll ('a', 'b' and total) contents were higher in IDC tolerant check ICGV 86031 (8.94 mg/kg; 1.462, 0.184 and $1.646 \mathrm{mg} / \mathrm{g}$ ) compared with susceptible check R 9227 $(5.33 \mathrm{mg} / \mathrm{kg} ; 0.377,0.067$ and $0.444 \mathrm{mg} / \mathrm{g})$, respectively. Accessions with high IDC tolerance belonging to different botanical varieties such as bypogaea bunch (ICG 5051) $(9.164 \mathrm{mg} / \mathrm{kg} ; 1.846,0.394$ and $2.240 \mathrm{mg} / \mathrm{g})$, vulgaris (ICG 11651) (9 mg/kg; 1.107, 0.194 and $1.300 \mathrm{mg} / \mathrm{g}$ ) and bypogaea runner (ICG 4156) $(6.213 \mathrm{mg} / \mathrm{kg} ; 0.561,0.091$, $0.652 \mathrm{mg} / \mathrm{g}$ ) had higher ferrous and chlorophyll (a, b and total) content, respectively. The highly significant negative 
Table 1. Genetic variability for IDC tolerance and yield-related traits for pooled data across 2 years in groundnut mini core

\begin{tabular}{|c|c|c|c|c|c|c|}
\hline Traits & Grand mean & Range & GCV & PCV & $H_{\mathrm{bs}}$ & GAM \\
\hline \multicolumn{7}{|l|}{ IDC tolerance traits } \\
\hline VCR $20 \mathrm{~d}$ & 1.42 & $1.06-3.03$ & 18.8 & 27.7 & 45.9 & 26.1 \\
\hline VCR $40 \mathrm{~d}$ & 1.76 & $1.20-2.98$ & 15.7 & 23.6 & 44.2 & 21.6 \\
\hline VCR $60 \mathrm{~d}$ & 2.54 & $1.83-3.42$ & 10.3 & 15.3 & 44.9 & 14.2 \\
\hline VCR $80 \mathrm{~d}$ & 2.65 & $1.35-4.12$ & 15.0 & 18.0 & 69.5 & 25.7 \\
\hline VCR $100 \mathrm{~d}$ & 2.83 & $1.79-3.75$ & 13.6 & 16.9 & 64.7 & 22.6 \\
\hline SCMR $20 \mathrm{~d}$ & 33.5 & $20.7-39.9$ & 7.5 & 10.1 & 54.2 & 11.3 \\
\hline SCMR $40 \mathrm{~d}$ & 30.5 & $19.7-36.5$ & 8.6 & 13.3 & 41.8 & 11.5 \\
\hline SCMR $60 \mathrm{~d}$ & 21.4 & $14.1-28.7$ & 10.8 & 16.3 & 43.7 & 14.6 \\
\hline SCMR $80 \mathrm{~d}$ & 21.9 & $11.7-36.2$ & 18.0 & 20.1 & 66.9 & 30.4 \\
\hline SCMR $100 \mathrm{~d}$ & 19.7 & $10.3-33.8$ & 22.0 & 25.0 & 64.4 & 33.2 \\
\hline \multicolumn{7}{|l|}{ Yield-related traits } \\
\hline Plant height $(\mathrm{cm})$ & 17.0 & $9.6-23.7$ & 11.4 & 16.6 & 47.4 & 16.2 \\
\hline No. of primary branches & 4.9 & $3.8-6.3$ & 7.16 & 11.3 & 40.2 & 9.3 \\
\hline No. of pods per plant & 7.1 & $2.2-12.7$ & 19.6 & 26.2 & 56.2 & 30.2 \\
\hline Pod yield (g/plant) & 3.9 & $1.2-6.3$ & 23.0 & 29.9 & 59.1 & 36.5 \\
\hline Shelling out turn (\%) & 57.3 & $49.3-65.3$ & 4.1 & 6.2 & 44.3 & 5.6 \\
\hline Hundred seed weight (g) & 28.5 & $17.2-37.8$ & 9.1 & 11.6 & 62.1 & 14.8 \\
\hline
\end{tabular}

VCR, visual chlorotic rating; SCMR, SPAD chlorophyll meter reading; d, days after sowing; GCV, genotypic coefficient of variation; PCV, phenotypic coefficient of variation; $H_{\mathrm{bs}}$, heritability broad sense; GAM, genetic advance as per cent of mean.

correlation was observed between VCR and SCMR at $60 \mathrm{~d}$ $(-0.947)$. VCR showed highly significant negative correlation with ferrous $(-0.707)$ and chlorophyll content $(a, b$, and total) $(-0.783,-0.721,-0.779)$, while SCMR showed highly significant positive correlation with ferrous (0.645) and chlorophyll content (a, b and total) $(0.725,0.671$, 0.721). Ferrous $\left(\mathrm{Fe}^{2+}\right)$ content showed significant positive correlation with chlorophyll 'a' (0.885), chlorophyll 'b' (0.795) and total chlorophyll (0.877) content.

\section{Mean comparison among botanical groups}

The group means and range for four different groups comprising mini core accessions belonging to six botanical varieties were estimated for IDC-related traits such as VCR and SCMR across five stages and also for yield-related traits (Table 2). During the severe stages of IDC incidence i.e. from 60 to $100 \mathrm{~d}$, group 3 (bypogaea bunch) was consistently tolerant to IDC followed by group 4 (bypogaea runner +hirsuta) and group 1 (vulgaris) as evident from significantly lesser VCR and higher SCMR group means. The group 2 (fastigiata + peruviana + aequatoriana) was distinctly susceptible to IDC as evident from significantly higher VCR and lesser SCMR group means. Among yield-related traits, group 3 (bypogaea bunch) was found superior for plant height and number of primary branches per plant, group 4 (bypogaea runner + hirsuta) for pod yield per plant and hundred seed weight and group 1 ( $v u l-$ garis) for number of pods per plant and shelling out-turn as evident from higher group means. Under iron deficiency stress, group 3 (bypogaea bunch) showed IDC tolerance and also better performance for yield-related traits.

\section{Promising IDC tolerant sources}

Evaluation of 184 accessions of the mini core along with controls (4) and checks (8) with varying degree of IDC response has led to the identification of IDC tolerant sources with significantly lesser VCR and higher SCMR values (Table 3). The most promising IDC tolerant accessions were ICG $5051(1.51,34.9)$ and ICG $6766(1.54,34.0)$ which recorded lowest mean VCR and highest mean SCMR values across five stages in comparison with the best IDC tolerant check ICGV $06146(1.62,32.5)$, respectively. At the most severe stage of IDC incidence, i.e.100 $\mathrm{d}$, the IDC tolerant accessions ICG $5051(1.79,33.8)$ and ICG $6766(1.83,32.7)$ recorded lower or on par VCR and SCMR values in comparison with the best IDC tolerant check ICGV 06146 (1.81, 30.5), respectively. Majority of the IDC tolerant accessions identified were from hypogaea bunch type viz. ICG \# 5051, 6766, 5286, 6667, 4538, 14008, 5663, 9842 and 11855 that recorded lower or on par VCR, 
Table 2. Range and mean comparison among four groups comprising six botanical varieties of groundnut mini core for VCR, SCMR and yield-related traits

\begin{tabular}{|c|c|c|c|c|c|c|c|c|}
\hline \multirow{2}{*}{ Traits } & \multicolumn{2}{|c|}{ Group 1 (vulgaris) } & \multicolumn{2}{|c|}{$\begin{array}{c}\text { Group } 2 \\
\text { (fastigiata }+ \text { peruviana }+ \\
\text { aequatoriana })\end{array}$} & \multicolumn{2}{|c|}{$\begin{array}{c}\text { Group } 3 \\
\text { (hypogaea bunch) }\end{array}$} & \multicolumn{2}{|c|}{$\begin{array}{c}\text { Group } 4 \\
\text { (hypogaea } \\
\text { runner + hirsuta) }\end{array}$} \\
\hline & Range & Mean $^{a}$ & Range & Mean $^{\mathrm{a}}$ & Range & Mean $^{a}$ & Range & Mean $^{a}$ \\
\hline VCR-20 d & $1.0-4.0$ & $1.41^{\mathrm{a}}$ & $1.0-4.0$ & $1.68^{\mathrm{b}}$ & $1.0-3.0$ & $1.27^{\mathrm{a}}$ & $1.0-2.0$ & $1.39^{\mathrm{a}}$ \\
\hline VCR-40 d & $1.0-4.0$ & $1.77^{\mathrm{b}}$ & $1.0-4.0$ & $1.88^{\mathrm{b}}$ & $1.0-3.0$ & $1.63^{\mathrm{a}}$ & $1.0-3.0$ & $1.80^{\mathrm{b}}$ \\
\hline VCR-60 d & $1.0-5.0$ & $2.65^{\mathrm{b}}$ & $1.0-4.0$ & $2.70^{\mathrm{b}}$ & $1.0-4.0$ & $2.44^{\mathrm{a}}$ & $1.0-4.0$ & $2.44^{\mathrm{a}}$ \\
\hline VCR-80 d & $1.0-5.0$ & $2.60^{\mathrm{b}}$ & $2.0-4.0$ & $2.97^{d}$ & $1.0-4.0$ & $2.45^{\mathrm{a}}$ & $1.0-4.0$ & $2.74^{\mathrm{c}}$ \\
\hline VCR-100 d & $1.0-5.0$ & $2.97^{\mathrm{c}}$ & $2.0-4.0$ & $3.13^{\mathrm{c}}$ & $1.0-4.0$ & $2.54^{\mathrm{a}}$ & $2.0-4.0$ & $2.80^{b}$ \\
\hline SCMR-20 d & $12.4-41.3$ & $32.8^{\mathrm{b}}$ & $11.4-45.7$ & $31.1^{\mathrm{c}}$ & $20.1-51.8$ & $35.0^{\mathrm{a}}$ & $26.9-46.3$ & $34.4^{\mathrm{a}}$ \\
\hline SCMR-40 d & $8.5-48.3$ & $30.3^{\mathrm{b}}$ & $9.6-48.2$ & $29.1^{\mathrm{b}}$ & $15.1-48.6$ & $32.2^{\mathrm{a}}$ & $14.5-45.1$ & $29.7^{\mathrm{b}}$ \\
\hline SCMR-60 d & $4.2-42.6$ & $19.7^{\mathrm{b}}$ & $3.0-37.1$ & $19.4^{\mathrm{b}}$ & $4.0-40.9$ & $22.0^{\mathrm{a}}$ & $6.8-39.1$ & $23.4^{\mathrm{a}}$ \\
\hline SCMR-80 d & $5.6-36.4$ & $22.0^{\mathrm{b}}$ & $5.5-34.2$ & $18.8^{\mathrm{c}}$ & $6.7-47.6$ & $24.2^{\mathrm{a}}$ & $5.3-35.6$ & $21.0^{\mathrm{b}}$ \\
\hline SCMR-100 d & $4.4-35.3$ & $18.1^{\mathrm{bc}}$ & $4.1-36.4$ & $16.6^{\mathrm{c}}$ & $5.5-50.1$ & $22.9^{a}$ & $4.4-34.7$ & $19.9^{b}$ \\
\hline PHT & $6.4-29.4$ & $16.8^{\mathrm{b}}$ & $7.8-27.8$ & $16.8^{\mathrm{b}}$ & $7.0-28.2$ & $17.9^{\mathrm{a}}$ & $9.0-27.8$ & $16.5^{\mathrm{b}}$ \\
\hline NPB & $2.4-8.8$ & $4.6^{b}$ & $3.0-6.6$ & $4.5^{\mathrm{b}}$ & $3.3-8.0$ & $5.2^{\mathrm{a}}$ & $2.4-8.2$ & $5.1^{\mathrm{a}}$ \\
\hline$N P$ & $2.0-16.0$ & $8.1^{\mathrm{a}}$ & $2.6-13.6$ & $6.0^{\mathrm{C}}$ & $1.5-13.6$ & $6.8^{b}$ & $2.2-13.6$ & $7.1^{b}$ \\
\hline PYP & $1.0-8.6$ & $4.0^{\mathrm{b}}$ & $1.1-7.5$ & $3.1^{\mathrm{d}}$ & $1.1-8.6$ & $3.6^{\mathrm{c}}$ & $1.1-10.0$ & $4.7^{\mathrm{a}}$ \\
\hline $\mathrm{SHO}$ & $42.7-72.7$ & $59.7^{\mathrm{a}}$ & $40.3-70.8$ & $56.6^{\mathrm{bc}}$ & $40.2-68.1$ & $55.4^{\mathrm{C}}$ & $41.6-69.4$ & $57.2^{\mathrm{b}}$ \\
\hline HSW & $14.6-40.7$ & $27.7^{\mathrm{c}}$ & $18.6-36.5$ & $27.3^{c}$ & $11.5-42.0$ & $29.2^{\mathrm{b}}$ & $22.0-41.4$ & $30.1^{\mathrm{a}}$ \\
\hline
\end{tabular}

VCR, visual chlorotic rating; SCMR, SPAD chlorophyll meter reading; d, days after sowing; PHT, plant height (cm); NPB, number of primary branches per plant; NP, number of pods per plant; PYP, pod yield (g/plant); SHO, shelling out-turn (\%); HSW, hundred seed weight (g).

${ }^{a}$ Mean comparison for each trait among different groups is depicted row-wise using Student-Newman-Keul's test at $P=0.05$; alphabets $(\mathrm{a}, \mathrm{b}, \mathrm{c}, \mathrm{d})$ followed by the group means in a row indicate the relative superiority of the respective group for the trait in that order (a-superior, $\mathrm{d}$-inferior); groups with same alphabets are similar in their response for the trait.

while higher or on par SCMR with IDC tolerant checks. However, few genotypes with IDC tolerance were also identified from hypogaea runner (ICG 10479), fastigiata (ICG 10890), and vulgaris (ICG 11651, ICG 118) that recorded lower or on par VCR, while higher or on par SCMR.

\section{Correlations}

The VCR and SCMR across five stages (20, 40, 60, 80 and 100 d) showed significant negative correlations between them (Online Supplementary Table S4). At most severe stages of IDC incidence (60, 80, $100 \mathrm{~d})$, VCR showed significant negative correlation with pod yield and its related traits such as the number of pods per plant, hundred seed weight, number of primary branches and plant height, while SCMR showed significant positive correlation with them. Pod yield under iron deficiency stress showed significant positive correlation with related traits such as number of pods, shelling out-turn, hundred seed weight, number of primary branches and plant height.

\section{Principal component analysis}

The PCA based on 16 characters i.e. VCR and SCMR across five stages, pod yield and its related traits revealed five major principal components (PC1, PC2, PC3, PC4 and PC5) that explained $80 \%$ of the total variation (online Supplementary Table S5). The PC1 explained $46.9 \%$ of the variation and was mainly contributed by VCR and SCMR across five stages. The PC2 which explained $11.4 \%$ of the variation was mainly contributed by shelling outturn, number of pods and pod yield. The PC3 that explained $9.2 \%$ of the variation was contributed by plant height, hundred seed weight, pod yield, number of primary branches and also VCR and SCMR at 20 and $40 \mathrm{~d}$. The PC4 which explained $6.8 \%$ of the variation was contributed by hundred seed weight, number of primary branches, VCR and SCMR at 20, 40, 80 and $100 \mathrm{~d}$. The PC5 that explained $5.6 \%$ of the variation was contributed by hundred seed weight, number of primary branches, plant height, VCR at 20 and $60 \mathrm{~d}$ and SCMR at $60 \mathrm{~d}$. The biplot generated using PC1 and PC2 explained $58.38 \%$ of the total variation 
Table 3. Promising IDC tolerant accessions identified in groundnut mini core belonging to four botanical varieties

\begin{tabular}{|c|c|c|c|c|c|c|c|c|c|c|c|c|c|c|c|c|}
\hline \multirow{2}{*}{$\begin{array}{l}\text { Botanical } \\
\text { variety/ICG } \\
\text { \#/Checks }\end{array}$} & \multirow{2}{*}{$\begin{array}{l}\text { Country } \\
\text { of origin/ } \\
\text { Institute }\end{array}$} & \multicolumn{6}{|c|}{ Visual chlorotic rating } & \multicolumn{6}{|c|}{ SPAD chlorophyll meter reading } & \multirow{2}{*}{$\begin{array}{c}\text { Pod } \\
\text { yield } \\
\text { (g/plant) }\end{array}$} & \multirow{2}{*}{$\begin{array}{c}\text { Shelling } \\
\text { out-turn } \\
(\%)\end{array}$} & \multirow{2}{*}{$\begin{array}{l}\text { Hundred } \\
\text { seed weight } \\
\text { (g) }\end{array}$} \\
\hline & & $20 d$ & $40 \mathrm{~d}$ & $60 d$ & $80 \mathrm{~d}$ & $100 \mathrm{~d}$ & Mean & $20 d$ & $40 \mathrm{~d}$ & $60 d$ & $80 d$ & $100 \mathrm{~d}$ & Mean & & & \\
\hline \multicolumn{17}{|l|}{ hypogaea bunch } \\
\hline 5051 & USA & 1.06 & 1.52 & 1.83 & 1.35 & 1.79 & 1.51 & 39.6 & 36.4 & 28.6 & 36.2 & 33.8 & 34.9 & 2.4 & 53.1 & 25.5 \\
\hline 6766 & USA & 1.11 & 1.32 & 1.88 & 1.54 & 1.83 & 1.54 & 39.9 & 36.5 & 28.7 & 32.1 & 32.7 & 34.0 & 4.4 & 59.0 & 27.8 \\
\hline 5286 & Zambia & 1.06 & 1.20 & 2.47 & 2.13 & 1.98 & 1.77 & 36.1 & 35.4 & 22.3 & 26.6 & 27.6 & 29.6 & 5.8 & 55.8 & 27.4 \\
\hline 6667 & USA & 1.30 & 1.48 & 2.20 & 2.32 & 1.83 & 1.83 & 35.3 & 34.9 & 26.9 & 24.3 & 29.4 & 30.2 & 2.8 & 51.1 & 29.3 \\
\hline 4538 & India & 1.07 & 1.37 & 2.78 & 2.18 & 2.17 & 1.91 & 38.3 & 36.2 & 24.2 & 24.8 & 27.8 & 30.2 & 2.9 & 58.1 & 24.9 \\
\hline 14,008 & CAR & 1.30 & 1.44 & 2.34 & 2.11 & 2.39 & 1.92 & 33.7 & 33.4 & 22.3 & 27.7 & 24.1 & 28.3 & 4.1 & 54.4 & 30.4 \\
\hline 5663 & China & 1.11 & 1.48 & 2.36 & 2.32 & 2.41 & 1.94 & 37.8 & 32.2 & 23.5 & 26.5 & 25.2 & 29.0 & 5.4 & 56.6 & 37.0 \\
\hline 9842 & Tanzania & 1.50 & 1.64 & 2.20 & 2.13 & 2.22 & 1.94 & 32.7 & 32.2 & 23.0 & 26.4 & 28.8 & 28.6 & 3.6 & 51.5 & 27.3 \\
\hline 11,855 & Korea & 1.11 & 1.76 & 2.22 & 2.33 & 2.38 & 1.96 & 36.0 & 31.7 & 23.6 & 23.9 & 22.6 & 27.6 & 3.9 & 54.5 & 35.8 \\
\hline \multicolumn{17}{|l|}{ hypogaea runner } \\
\hline 10,479 & Uruguay & 1.10 & 1.59 & 2.10 & 2.16 & 2.40 & 1.87 & 37.3 & 34.6 & 25.0 & 28.4 & 24.7 & 30.0 & 1.8 & 55.0 & 27.8 \\
\hline \multicolumn{17}{|l|}{ Fastigiata } \\
\hline 10,890 & Peru & 1.11 & 1.80 & 2.04 & 2.13 & 2.22 & 1.86 & 35.8 & 31.9 & 26.7 & 26.6 & 24.6 & 29.1 & 3.6 & 55.6 & 20.6 \\
\hline \multicolumn{17}{|l|}{ Vulgaris } \\
\hline 11,651 & China & 1.30 & 1.65 & 2.00 & 2.29 & 2.22 & 1.89 & 33.4 & 32.9 & 23.8 & 24.8 & 25.1 & 28.0 & 6.1 & 60.6 & 32.2 \\
\hline 118 & India & 1.46 & 1.53 & 2.14 & 2.18 & 2.36 & 1.93 & 34.7 & 33.2 & 26.0 & 25.2 & 23.3 & 28.5 & 5.2 & 56.8 & 37.8 \\
\hline \multicolumn{17}{|l|}{ Checks $^{\mathrm{a}}$} \\
\hline ICGV 06146 & ICRISAT & 1.11 & 1.44 & 2.02 & 1.72 & 1.81 & 1.62 & 38.9 & 33.9 & 27.7 & 31.4 & 30.5 & 32.5 & 5.1 & 51.3 & 27.1 \\
\hline A30b & UASD & 1.11 & 1.28 & 1.86 & 2.11 & 2.00 & 1.67 & 39.2 & 35.7 & 27.8 & 29.1 & 30.3 & 32.4 & 3.0 & 57.3 & 30.7 \\
\hline ICGV 86031 & ICRISAT & 1.30 & 1.76 & 2.02 & 1.92 & 2.00 & 1.80 & 37.2 & 31.4 & 27.1 & 29.8 & 29.8 & 31.0 & 6.2 & 58.7 & 29.2 \\
\hline R 9227 & UASD & 1.49 & 2.08 & 3.14 & 2.89 & 3.15 & 2.55 & 32.0 & 27.3 & 16.0 & 18.2 & 16.0 & 21.9 & 2.9 & 55.4 & 25.9 \\
\hline TMV 2 & TNAU & 1.11 & 1.92 & 2.66 & 2.70 & 2.96 & 2.27 & 34.1 & 29.4 & 20.0 & 20.4 & 17.7 & 24.3 & 4.4 & 58.9 & 30.1 \\
\hline $\operatorname{LSD}(P=0.05)$ & - & 0.52 & 0.61 & 0.57 & 0.62 & 0.63 & - & 4.7 & 5.9 & 5.1 & 6.5 & 6.5 & - & 1.1 & 3.5 & 2.7 \\
\hline CV (\%) & - & 26.7 & 28.2 & 18.4 & 16.9 & 16.4 & - & 10.7 & 15.4 & 19.7 & 22.1 & 23.8 & - & 17.7 & 3.9 & 6.1 \\
\hline
\end{tabular}

CAR, Central African Republic; ICRISAT, International Crops Research Institute for the Semi-Arid Tropics; UASD, University of Agricultural Sciences Dharwad; TNAU, Tamil Nadu Agricultural University; d, days after sowing.

a IDC tolerant checks - ICGV06146, ICGV 86031 (vulgaris), A30b (hypogaea bunch); IDC susceptible checks - R 9227, TMV 2 (vulgaris). 
(Fig. 1). The distribution of genotypes was based on their IDC response wherein, tolerant genotypes were distinctly separated from susceptible ones. The VCR and SCMR at later stages showed higher variation than early stages indicating better differentiation of genotypes. The VCR and SCMR across all five stages were distinctly negatively related as they are positioned in opposite direction in the biplot. The traits such as shelling out-turn, number of pods and pod yield showed the highest variation as they were farthest from the centre.

\section{Hierarchical clustering}

The hierarchical clustering using Euclidian distances of five major principal components revealed seven major clusters (I-VII) (Fig. 2) with each cluster having accessions from one to six different botanical varieties (Table 4). The clustering was mainly based on the IDC response of accessions as measured by VCR and SCMR across five stages. The cluster VII had IDC tolerant mini core accessions (ICG 5051, 6766) and checks (A30b, ICGV06146) with very low VCR (1.58) and very high SCMR (33.4) cluster mean values across five stages. The clusters IV $(2.04,27.5)$ and II $(2.07,26.9)$ had mini core accessions $(38,26$ accessions) and checks/controls (ICGV 86031, DSG 1, GPBD 5, ICG 13941, ICG 13942) that were moderately tolerant to IDC as evident from lower VCR and higher SCMR cluster mean values, respectively. The clusters I $(2.21,25.5)$, III $(2.30,24.7)$, and $\mathrm{V}(2.53,22.6)$ had mini core accessions (41, 40, 30 accessions, respectively) and checks/controls (GPBD 4, TMV 2, R 9227, ICG 156, ICG 2738) that were moderately susceptible to IDC as evident from moderately higher VCR and lower SCMR cluster mean values, respectively. The cluster VI had eight mini core accessions that were susceptible to IDC as evident from higher VCR (2.92) and lower SCMR (19.4) cluster mean values. The intracluster variance was highest for cluster VI (14.266) followed by clusters VII (6.616), IV (5.47), II (5.2), V (4.846), III (4.187) and I (4.183) (Table 4). The intercluster distance between clusters VI and VII was highest (14.684) followed by between clusters V and VII (10.876) (online Supplementary Table S6). The clusters VI and VII were farthest from the remaining clusters (I-V).

\section{Discussion}

Groundnut grown under calcareous and alkaline soils displays IDC that causes significant reduction in pod yield in countries such as India (Singh et al., 1995; Singh, 2001), China (Gao and Shi, 2007) and Pakistan (Imtiaz et al., 2010; Akhtar et al., 2013). Under extreme cases, IDC may also lead to complete crop failure. The most economical and sustainable solution to combat IDC is to develop groundnut cultivars with a high level of tolerance to IDC as they perform well under Fe-deficient conditions (Samdur et al., 1999; Prasad et al., 2000; Gao and Shi, 2007). Groundnut improvement for IDC tolerance requires the availability of highly tolerant and diverse sources. Since the global collections of groundnut germplasm have a very large number of accessions, they are not ideal for evaluation. The mini-core collection of groundnut comprising 184 accessions representing the diversity of the entire collection (Upadhyaya et al., 2002) provides an opportunity for evaluation and identification of diverse sources of IDC tolerance. The mini-core collection that was evaluated for IDC response in iron-deficient calcareous soils displayed enormous genotypic differences among the accessions for IDC related traits such as VCR and SCMR across five stages (20, 40, 60, 80 and 100 days) as evident from wide range of variation (online Supplementary Table S2, Table 1). The genetic components of variability such as GCV and PCV showed moderate to high genotypic differences for VCR, SCMR, pod yield, number of pods per plant, plant height and hundred seed weight among mini core accessions (Table 1). Moderate to high heritability and GAM values for VCR and SCMR at a severe stage of IDC and also for pod yield, number of pods, plant height and hundred seed weight among mini core accessions suggest that we can make improvement for IDC tolerance and also pod yield by performing selection under iron deficiency stress. Earlier, genotypic differences for IDC response as measured by VCR and SPAD values have been noted among groundnut germplasm (Samdur et al., 1999, 2000; Gao and Shi, 2007; Akhtar et al., 2013; Su et al., 2015). The traits such as VCR and SCMR have been established as extremely useful for preliminary and large-scale screening of germplasm or breeding material for IDC response due to their simplicity and robustness (Gao and Shi, 2007; Boodi et al., 2015a, b).

In groundnut, earlier reports suggest the beginning of iron deficiency at 10-15 days after emergence, while attaining of maximum intensity at 30-70 days (Singh and Chaudhari, 1993) or 50-65 days after emergence (Li et al., 2009a). In this study also the severity of IDC was found increasing from the initial $(20 \mathrm{~d})$ to later $(40,60 \mathrm{~d})$ stages as evident from the increase in VCR scores and decrease in SCMR values. Further increase in IDC severity at much later stages $(80,100 \mathrm{~d})$ in this study was due to the occurrence of rain or protective irrigation provided during these stages.

Enormous differences were also observed among the mini core accessions for pod yield and its related traits such plant height, number of primary branches, number of mature pods per plant, shelling out turn and hundred seed weight indicating the genotypic differences for these traits in mini core under iron deficiency stress (online Supplementary Table S2, Table 1). As noted in this study, 
Biplot (axes PC1 and PC2: $\mathbf{5 8 . 3 8 \% )}$

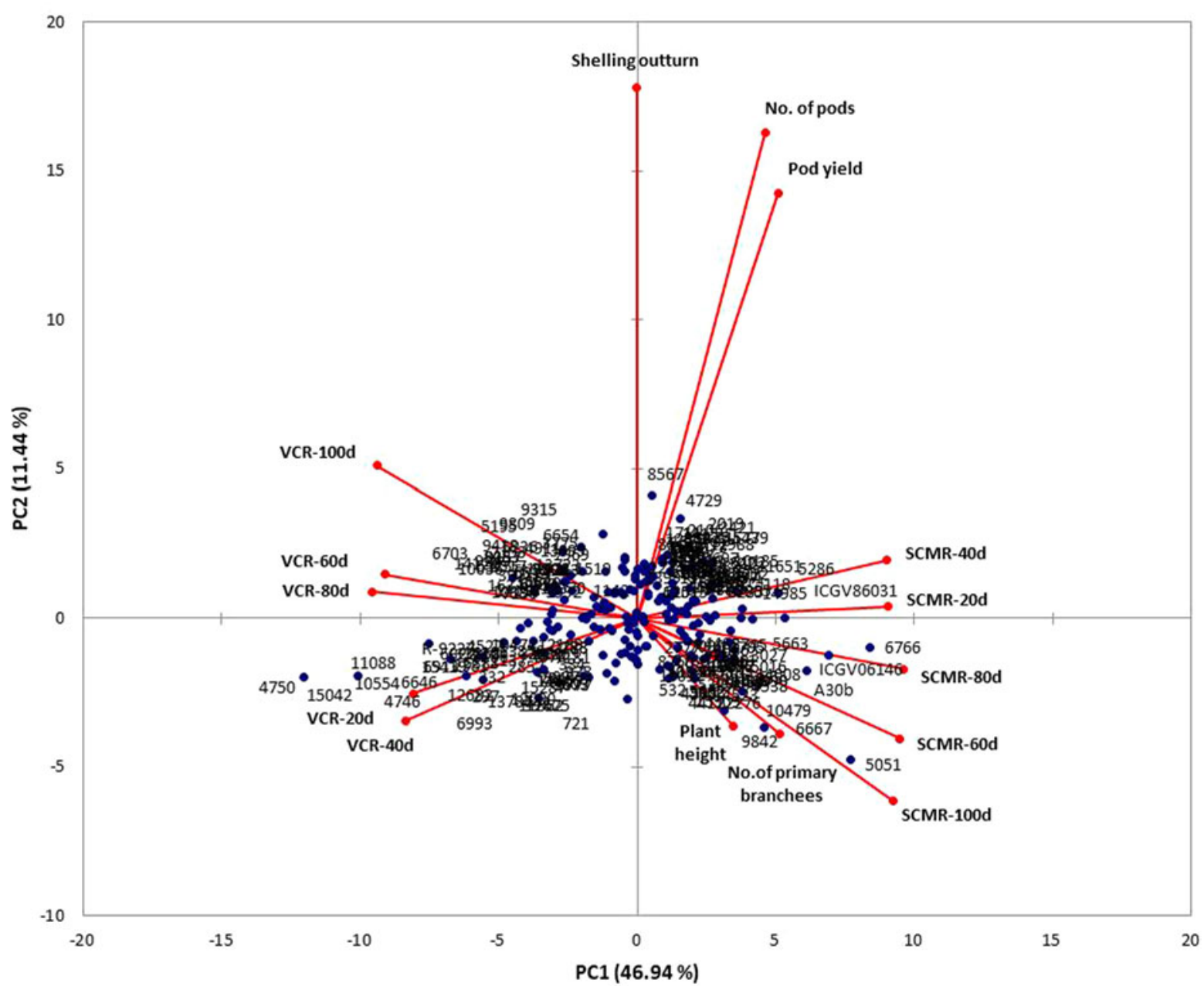

Fig. 1. Biplot depicting distribution of genotypes and IDC tolerance and yield-related traits.

moderate to severe yield reductions among IDC susceptible genotypes were reported earlier in groundnut (Singh et al., 1995; Singh, 2001). IDC tolerant genotypes have been found to show higher pod yield and its related traits compared with susceptible genotypes as noted earlier in groundnut (Akhtar et al., 2013). Reduction in pod yield among selected IDC tolerant genotypes under Fe-applied and Fe-stress conditions need to be critically assessed to unravel the yield contributing traits under IDC stress.

Iron deficiency leads to interveinal chlorosis which results in reduced chlorophyll content that may or may not get noticed through visual scoring for chlorosis. The reduction of chlorophyll content in leaves is at least in part due to the role of $\mathrm{Fe}$ in the formation of precursors of the chlorophyll molecule i.e., $\delta$-aminolevulinic acid and protochlorophyllide (Marschner, 1986). Chlorotic plants have been earlier found to show lesser active Fe $\left(\mathrm{Fe}^{2+}\right)$ content in leaves (Singh, 1994). To establish the associations between IDC, chlorophyll ( $\mathrm{a}, \mathrm{b}$ and total), and active $\mathrm{Fe}\left(\mathrm{Ferrous}, \mathrm{Fe}^{2+}\right.$ ) content, they were estimated among 16 representative accessions of mini core with varying IDC response (tolerant to susceptible) along with checks at most severe stage of IDC response (60 d) during rainy season of 2014 (online Supplementary Table S3). Tolerant genotypes had higher chlorophyll and active Fe content compared with susceptible genotypes irrespective of the botanical variety they belonged to. The leaves of chlorotic plants have been earlier found to have lesser chlorophyll (Samdur et al., 2000) and active Fe content (Singh, 1994) in groundnut. The significant positive correlation was observed between active Fe and chlorophyll ( $\mathrm{a}, \mathrm{b}$ and total) content with SCMR, while the significant negative correlation with VCR. Active Fe content showed significant positive correlation with chlorophyll (a, b and total) as noted earlier in groundnut (Akhtar et al., 2013). These results of chlorophyll and active Fe content along with VCR and SCMR values at the most severe stage of IDC incidence confirm the genotypic 


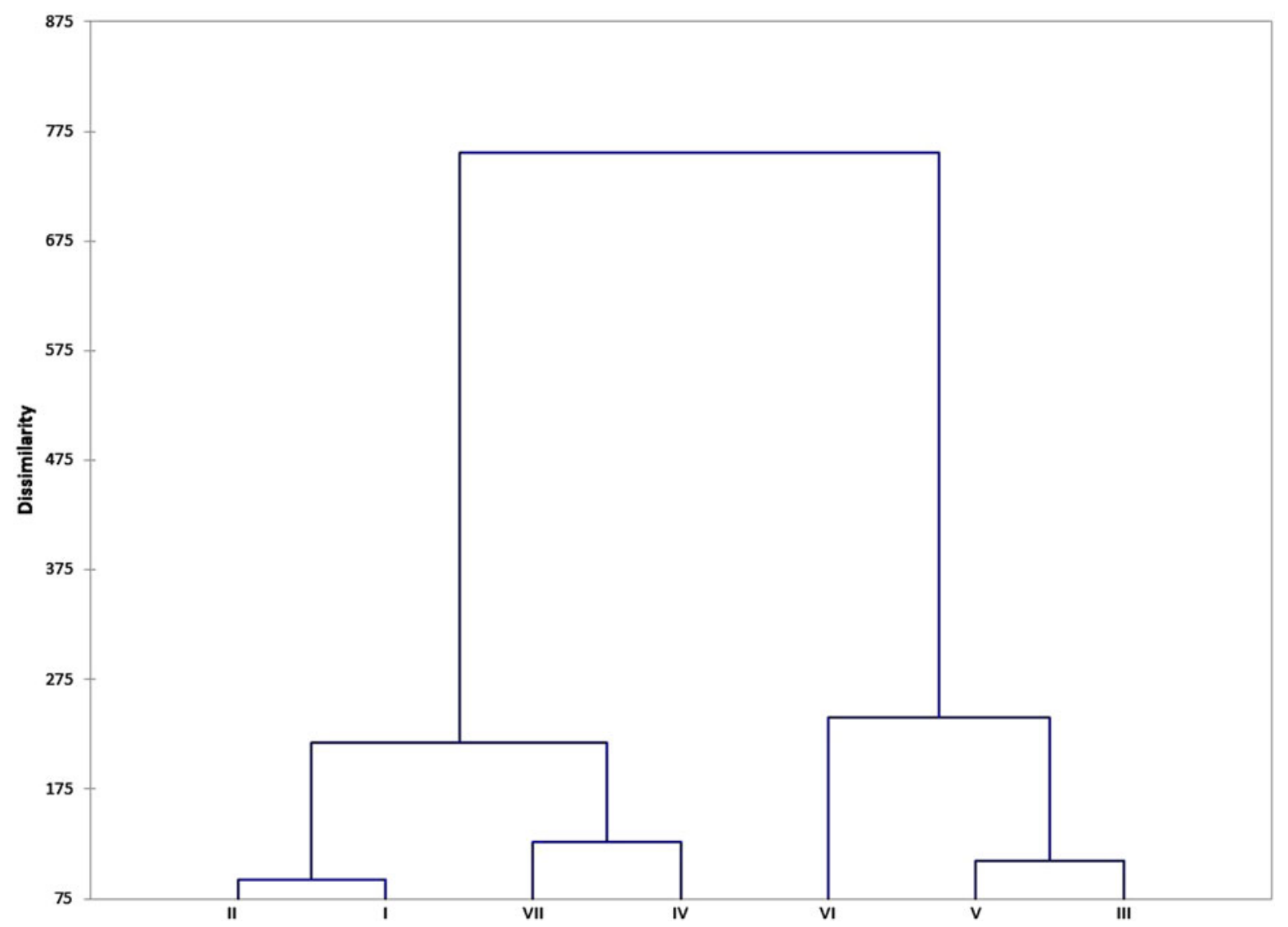

Fig. 2. Dendrogram depicting seven clusters based on dissimilarity.

differences for IDC response at a biochemical level among the mini core accessions.

The significant negative correlations were observed between VCR and SCMR across five growth stages (online Supplementary Table S4) as noted earlier in groundnut (Boodi et al., 2015b). During the severe stages of IDC incidence $(60,80,100 \mathrm{~d})$, VCR showed significant negative correlation, while SCMR showed significant positive correlation with pod yield and its related traits such as number of pods, hundred seed weight, number of primary branches and plant height as noted earlier in groundnut (Boodi et al., 2015b). Under iron deficiency stress, pod yield showed significant positive correlation with related traits such as number of pods, shelling out-turn, hundred seed weight, number of primary branches and plant height indicating that these traits contribute for pod yield under IDC. Further, SPAD is an indirect indicator of chlorophyll content as significant correlations have been established earlier in groundnut (Samdur et al., 2000; Boodi et al., 2015b). The SCMR values are more robust and suitable than the estimation of chlorophyll content for large-scale screening of groundnut genotypes for IDC response. The active Fe content has been shown as an important indicator of IDC tolerance among groundnut genotypes (Reddy et al., 1993;
Singh, 1994; Gao and Shi, 2007; Li et al., 2009b). For confirmation of identified sources of IDC tolerance, estimations such as chlorophyll and active Fe content will be done across several growth stages of groundnut.

Evaluation of groundnut mini core has led to the identification of 13 IDC tolerant sources belonging to different botanical varieties which displayed lesser VCR and higher SCMR values in comparison to IDC tolerant checks (Table 3). The most promising IDC tolerant accessions were ICG 5051 and ICG 6766 belonging to bypogaea bunch type. Majority of the IDC tolerant accessions identified were from hypogaea bunch type with few accessions from hypogaea runner, fastigiata and vulgaris. The IDC tolerance sources identified were irrespective of the country of their origin. This is the first report which indicates a higher degree of IDC tolerance among bypogaea bunch type of groundnut. Grouping of the mini core accessions by PCA and hierarchical clustering was mainly based on their IDC response. There was distinct clustering of mini core accessions/controls/checks that were tolerant, moderately tolerant, moderately susceptible, or susceptible to IDC (Fig. 1, Table 4, Fig. 2). The IDC tolerant accessions (ICG 5051, ICG 6766) and checks (A30b, ICGV06146) formed a distinct cluster VII (Fig. 2). These results are in collinearity with 
Table 4. Hierarchical clustering of mini core accessions, controls, and checks belonging to six botanical varieties

\begin{tabular}{|c|c|c|c|c|c|}
\hline Cluster & $\begin{array}{l}\text { Intra-cluster } \\
\text { variance }\end{array}$ & $\begin{array}{l}\text { VCR } \\
\text { Mean }\end{array}$ & $\begin{array}{l}\text { SCMR } \\
\text { Mean }\end{array}$ & $\begin{array}{l}\text { No. of } \\
\text { genotypes }\end{array}$ & Botanical varieties/Mini core accessions/Controls (c)/Checks \\
\hline I & 4.183 & 2.21 & 25.5 & 43 & $\begin{array}{l}\text { vulgaris - ICG \# 36, 81, 1415, 1415, 1973, 2019, 3102, 3421, 3746, } \\
3775,4543,4684,4729,4911,5779,6263,6654,7969,8567,9507, \\
\text { 11249, 11687, 12697, 12879, 12921, 12988, GPBD-4, TMV-2; } \\
\text { fastigiata - ICG \# 1399, 1711, 4670, 9315; hypogaea bunch - ICG \# } \\
\text { 188, 6402, 7963; hypogaea runner - ICG \# } 156 \text { (c), 862, 875, 2777, } \\
\text { 8490, 8760, 11219, 13099, } 13723\end{array}$ \\
\hline II & 5.200 & 2.07 & 26.9 & 29 & $\begin{array}{l}\text { vulgaris - ICG \# 434, 2106, 3240, 4955, 13603, GPBD-5; fastigiata - ICG } \\
\# 3673,5475,5609,10890,11144,14710,15309 ; \text { hypogaea bunch - } \\
\text { ICG \# 111, 4538, 4598, 6892, 7000, 11426, 12672, } 13941 \text { (c), } 13942 \\
\text { (c), 13982, 14523, 14705; hypogaea runner - ICG \# 9905, 10479, } \\
\text { 11457, 12370 }\end{array}$ \\
\hline III & 4.187 & 2.30 & 24.7 & 41 & $\begin{array}{l}\text { vulgaris - ICG \#334, 442, 3343, 3584, 6407, 7190, 7906, 10384, 11515, } \\
\text { 14118, 15287; fastigiata - ICG \# 115, 1274, } 2738 \text { (c), 3681, 5221, } \\
\text { 6201, 7181, 10092, 10474, 10566, 12189, 13856, 14630; hypogaea } \\
\text { bunch - ICG \# 532, 721, 9777, 11862, 12000, 13787, 14466; } \\
\text { hypogaea runner - ICG \# 928, 2511, 2773, 2857, 3992, 4343, 6813, } \\
\text { 7243, 9037, } 11109\end{array}$ \\
\hline IV & 5.470 & 2.04 & 27.5 & 40 & $\begin{array}{l}\text { vulgaris - ICG \# } 118,5494,11651,13491,14985, \text { ICGV-86031; } \\
\text { hypogaea bunch - ICG \# 513, 1668, 2772, 3027, 3053, 5286, 5327, } \\
\text { 5662, 5663, 5745, 5891,6057, 6667, 8285, 9666, 9842, 9961, 10185, } \\
\text { 11322, 11855, 12276, 14008, 14475, 14482, 15190; hypogaea runner } \\
\text { - ICG \# 76, 2925, 4156, 4389, 4412, 4998, 5016, 5827, DSG-1 }\end{array}$ \\
\hline V & 4.846 & 2.53 & 22.6 & 31 & $\begin{array}{l}\text { vulgaris - ICG \# } 1137,1519,5195,5236,6375,8083,9157,9249,9418, \\
\text { 9809, 12682, R-9227; fastigiata - ICG \# 297, 332, 397, 1142, 6022, } \\
\text { 6888, 8106, 8517, 13858, 14106, 14127; peruviana - ICG 10036; } \\
\text { hypogaea bunch - ICG \# 4527, 6703; hypogaea runner - ICG \# 163, } \\
\text { 2381, 6993, 7153; hirsuta - ICG 15419 }\end{array}$ \\
\hline VI & 14.266 & 2.92 & 19.4 & 8 & $\begin{array}{l}\text { vulgaris - ICG 4750; fastigiata - ICG \# 6646, 10554, 15042; peruviana - } \\
\text { ICG 11088; aequatoriana - ICG 12625; hypogaea bunch - ICG \# 4746, } \\
6913\end{array}$ \\
\hline VII & 6.616 & 1.58 & 33.4 & 4 & vulgaris - A30b, ICGV-06146; hypogaea bunch - ICG \# 5051, 6766 \\
\hline
\end{tabular}

lower VCR and higher SCMR values recorded by these accessions (Table 3). The identified IDC tolerant sources need to be studied in detail including biochemical investigations for confirmation of IDC tolerance. The confirmed sources of IDC tolerance can be crossed with high yielding and adapted groundnut cultivars to develop high yielding and IDC tolerant groundnut varieties for cultivation in irondeficient calcareous and alkaline soils.

\section{Supplementary material}

The supplementary material for this article can be found at https://doi.org/10.1017/S1479262117000326.

\section{Acknowledgements}

Authors are grateful to Dr H. D. Upadhyaya, Head Genebank, ICRISAT, Patancheru (India) for providing seeds of mini-core collection of groundnut for evaluation and staff of Department of Genetics and Plant Breeding, College of Agriculture, Vijayapur for their support in conducting the field trial. Authors also declare that there is no conflict of interest with regard to the research undertaken.

\section{References}

Akhtar S, Shahzad A, Arshad M and Fayyaz-Ul-Hassan (2013) Morpho-physiological evaluation of groundnut (Arachis bypogaea L.) genotypes for iron deficiency tolerance. Pakistan Journal of Botany 45: 893-899. https://www. pakbs.org/pjbot/PDFs/45(3)/23.pdf

Arnon DI (1949) Copper enzyme in isolated chloroplasts polyphenol in Beta vulgaris. Plant Physiology 24: 1-15.

Boodi IH, Pattanashetti SK and Biradar BD (2015a) Identification of groundnut genotypes resistant to iron deficiency chlorosis. Karnataka Journal of Agricultural Sciences 28: 406-408.

Boodi IH, Pattanashetti SK, Biradar BD, Naidu GK, Chimmad VP, Kanatti A, Kumar V and Debnath MK (2015b) Morphophysiological parameters associated with iron deficiency chlorosis resistance and their effect on yield and its related 
traits in groundnut. Journal of Crop Science and Biotechnology 19: 177-187. doi: 10.1007/s12892-016-0005-8.

Burton GN and Devane EM (1953) Estimating heritability in fall fescue (Festuca arundiancea L.) from replicated clonal material. Agronomy Journal 45: 478-481.

Cakmak I (2002) Plant nutrition research: priorities to meet human needs for food in sustainable way. Plant and Soil 247: 3-24. doi: 10.1023/A:1021194511492.

Frankel OH (1984) Genetic perspective of germplasm conservation. In: Arber W, Limensee K, Peacock WJ and Stralinger $\mathrm{P}$ (eds) Genetic Manipulations: Impact on man and Society. Cambridge, UK: Cambridge University Press, pp. 161-170.

Gao L and Shi YX (2007) Genetic differences in resistance to iron deficiency chlorosis in peanut. Journal of Plant Nutrition 30 (1-3): 37-52. doi: 10.1080/01904160601054965.

Guerinot ML and Yi Y (1994) Iron: nutritious, noxious and not readily available. Plant Physiology 104: 815-820. https:// www.ncbi.nlm.nih.gov/pmc/articles/PMC160677/pdf/1040815. pdf.

Hanson GH, Robinson HF and Comstock RE (1956) Biometrical studies of yield in segregating population of Korean lespodzoa. Agronomy Journal 48: 267-282.

Hüve K, Remus R, Lüttschwager D and Merbach W (2003) Transport of foliar-applied iron $\left({ }^{59} \mathrm{Fe}\right)$ in Vicia faba. Journal of Plant Nutrition 26: 2231-2242. doi: 10.1081/PLN120024277.

Imtiaz M, Rashid A, Khan P, Memon MY and Aslam M (2010) The role of micronutrients in crop production and human health. Pakistan Journal of Botany 42: 2565-2578. http://www. pakbs.org/pjbot/PDFs/42(4)/PJB42(4)2565.pdf

Johnson HW, Robinson HF and Comstock HF (1955) Estimates of genetic and environmental variability in soybean. Agronomy Journal 47: 314-318.

Katyal JC and Sharma BD (1980) A new technique of plant analysis to resolve iron chlorosis. Plant and Soil 55: 105-119. doi: 10.1007/BF02149714.

Keuls M (1952) The use of the "studentized range" in connection with an analysis of variance. Euphytica 1: 112-122.

Laurie SH, Tancock NP, Mcgrath SP and Sanders JR (1991). Influence of complexation on the uptake by plants of iron, manganese, copper and zinc. Journal of Experimental Botany 42: 509-513. doi: 10.1093/jxb/42.4.515.

Li G, YanXi S and JianMin Z (2009a) Study on the sensitive period and screening index for iron deficiency chlorosis in peanut. Plant Nutrition and Fertilizer Science 15: 917-922. http://en. cnki.com.cn/Article_en/CJFDTOTAL-ZWYF200904028.htm.

Li G, YanXi S and JianMin Z (2009b) Genetic differences in iron nutrient characteristic of different peanut cultivars with resistance to iron deficiency. Chinese Journal of Soil Science 40: 1393-1397. http://jglobal.jst.go.jp/en/public/2016022 96125914201

Marschner H (1986) Mineral Nutrition of Higher Plants (1st edition). Orlando, Florida, USA: Academic Press.

Newman D (1939) The distribution of range in samples from a normal population expressed in terms of an independent estimate of standard deviation. Biometrica 31: 20-30.

Prasad PVV, Satyanarayana V, Potdar MV and Craufurd PQ (2000) On-farm diagnosis and management of iron chlorosis in groundnut. Journal of Plant Nutrition 23: 1471-1483. doi: 10.1080/01904160009382115.

Patterson HD and Thompson R (1971) Recovery of inter block information when block sizes are unequal. Biometrika 58 : 545-554. doi: 10.1093/biomet/58.3.545.
Reddy KB, Ashalatha M and Venkaiah K (1993) Differential response of groundnut genotypes to iron-deficiency stress. Journal of Plant Nutrition 16: 523-531. doi: 10.1080/ 01904169309364551.

Robinson HF, Comstock RF and Harrey PH (1949) Estimates of heritability and degree of dominance in corn. Agronomy Journal 41: 353-359.

Samdur MY, Mathur RK, Manivel P, Singh AL, Bandyopadhyay A and Chikani BM (1999) Screening of some advanced breeding lines of groundnut (Arachis hypogaea) for tolerance of lime-induced iron-deficiency chlorosis. Indian Journal of Agricultural Sciences 69: 722-725.

Samdur MY, Singh AL, Mathur RK, Manivel P, Chikani BM, Gor HK and Khan MA (2000) Field evaluation of chlorophyll meter for screening groundnut (Arachis hypogaea L.) genotypes tolerant to iron-deficiency chlorosis. Current Science 79: 211-214. http://www.iisc.ernet.in/currsci/jul252000/ Samdur.pdf.

Sánchez-Alcalá I, delCampillo MD, Barrón V and Torrent J (2014) Evaluation of preflooding effects on iron extractability and phytoavailability in highly calcareous soil in containers. Journal of Plant Nutrition and Soil Science 177: 150-158. doi: 10.1002/jpln.201200302.

Shoaf TW and Lium BW (1976) Improved extraction of chlorophyll 'a' and 'b' from algae using dimethyl sulfoxide. Limnology and Oceanography 21: 926-928. doi: 10.4319/lo.1976.21.6. 0926.

Singh AL (1994) Micronutrients nutrition and crop productivity in groundnut. In: Singh K and Purohit SS (ed) Plant Productivity Under Environment Stress. Bikaner, India: Agrobotanical publishers, pp. 67-72.

Singh AL (2001) Yield losses in groundnut due to micronutrient deficiencies in calcareous soils of India. In: Plant Nutrition: Food Security and Sustainability of Agro-Ecosystems Through Basic and Applied Research. Hannover, Germany: 14th International Plant Nutrition Colloquium, pp. 838-839.

Singh AL (2004) Mineral nutrient requirement, their disorders and remedies in groundnut. In: Basu MS and Singh NB (eds) Groundnut Research in India. Junagadh, India: National Research Center for Groundnut (ICAR), pp. 137-159.

Singh AL and Chaudhari V (1993) Screening of groundnut germplasm collection and selection of genotypes tolerant of lime-induced iron-chlorosis. Journal of Agriculture Sciences (Cambridge) 121: 205-211. doi: 10.1017/S002185 9600077078.

Singh AL, Chaudhari V, Koradia VG and Zala PV (1995) Effect of excess irrigation and iron and sulphur fertilizers on the chlorosis, dry matter production, yield and nutrients uptake by groundnut in calcareous soil. Agrochimica 39: 184-198.

Singh AL, Basu MS and Singh NB (2004) Mineral Disorders of Groundnut. National Research Centre for Groundnut (ICAR), Junagadh, India, p. 30.

Sivasubramanian S and Menon M (1973) Heterosis and inbreeding depression in rice. Madras Agricultural Journal 60: 11391140.

Su Y, Zhang Z, Su G, Liu J, Liu C and Shi G (2015) Genotypic differences in spectral and photosynthetic response of peanut to iron deficiency. Journal of Plant Nutrition 38: 145160. doi: 10.1080/01904167.2014.920392.

Upadhyaya HD and Ortiz R (2001) A mini core subset for capturing diversity and promoting utilization of chickpea genetic resources in crop improvement. Theoretical and Applied Genetics 102: 1292-1298. doi: 10.1007/s00122-001-0556-y. 
Upadhyaya HD, Bramel PJ, Ortiz R and Singh S (2002) Developing a mini core of peanut for utilization of genetic resources. Crop Science 42: 2150-2156. doi: 10.2135/cropsci2002.2150.

Upadhyaya HD, Dwivedi SL, Vadez V, Hamidou F, Singh S, Varshney RK and Liao B (2014) Multiple resistant and nutritionally dense germplasm identified from mini core collection in peanut. Crop Science 54: 679-693. doi: 10.2135/ cropsci2013.07.0493.

VSN International (2011) GenStat Software for Windows. Release 14.1.VSN International Ltd., Hemel Hempstead, UK.

Wald A (1943) Test of statistical hypothesis concerning several parameters when the number of observations is large.
Transactions of the American Mathematical Society 54: 426-482.

Ward J (1963) Hierarchical grouping to optimize an objective function. Journal of American Statistical Association 38: 236-244.

Ye LX, Li L, Wang L, Wang S, Li S, Du J, Zhang S and Shou H (2015) MPK3/MPK6 are involved in iron deficiency-induced ethylene production in Arabidopsis. Frontiers in Plant Science 6: 953. doi: 10.3389/fpls.2015.00953.

Zuo YM and Zhang FS (2011) Soil and crop management strategies to prevent iron deficiency in crops. Plant and Soil 339: 8395. doi: 10.1007/s11104-010-0566-0. 